\title{
REFLEXÕES SOBRE O PAPEL DO PROFESSOR E DO ESTUDANTE NA EDUCAÇÃO A DISTÂNCIA
}

\section{Reflections on the role of the teacher and the student in distance education}

Aryane Raysa Araújo dos Santos ${ }^{1}$

Danillo Moretti Godinho Linhares (IFPI) ${ }^{2}$

RESUMO: Este artigo é resultado de uma pesquisa bibliográfica acerca do papel e das competências específicas do professor e do estudante na educação a distância $(E a D)$ à luz da teoria construtivista. O presente artigo tem por objetivo apresentar uma visão dos principais atores desse cenário tão importante na educação brasileira que é a EaD. Nesse sentido, definimos, em linhas gerais, o papel do professor (educador) como o de mediador do conhecimento, capaz de produzir materiais e conteúdo que desenvolvam o senso crítico e a autonomia intelectual de seus alunos, de acordo com as características dessa modalidade de ensino. Nesse viés, o aluno deve reconhecer-se como coautor do conhecimento, um indivíduo capaz de realizar uma análise crítica e uma síntese pessoal dos temas estudados.

Palavras-chave: EaD. Professor. Estudante.

ABSTRACT: This paper is the result of a bibliographic research on the role and specific competences of the teacher and the student in the distance education (D.E.) under the light of the constructivist theory. The present paper aims to present a vision of the main actors of this important scenario in Brazilian education, which is the D.E. In this sense, we define in general terms the role of the teacher (educator) as the mediator of knowledge, capable of produce materials and contents that develop the critical sense and intellectual autonomy of their students according to the characteristics of this teaching mode. In turn, the student should recognize himself as a co-author of knowledge, as an individual capable of critical analysis and personal synthesis of the topics covered.

Keywords: D.E. Professor. Student.

\footnotetext{
${ }_{1}^{1}$ Mestre em Filosofia pela UFPI

${ }^{2}$ Mestre em Filosofia pela UFPi e Prof. De Filosofia do IFPI. 


\section{INTRODUÇÃO}

Ao longo da história, a educação a distância foi caracterizada em várias gerações. A primeira, refere-se aos cursos de instruções que eram entregues pelos correios, eram chamados de estudo por correspondência. A segunda, diz respeito ao ensino por meio do rádio e da televisão. A terceira, foi marcada pela invenção de uma nova modalidade de organização da educação, temos como exemplo dessa modalidade, a universidade aberta.

Em seguida, no ano de 1980, tivemos a quarta geração da educação a distância, que foi a teleconferência. E, por fim, a quinta, na qual manteremos nossa atenção, é a modalidade mais recente de educação a distância, trata-se do ensino, baseado na tecnologia da internet ${ }^{3}$.

Em linhas gerais, compreendemos a $\mathrm{EaD}$, de acordo com a definição de LITWIN ${ }^{4}$, como uma modalidade de ensino, portadora de características específicas, a saber: "uma maneira particular de criar um espaço para gerar, promover e implementar situações em que os alunos aprendam". Ou seja, o processo de ensino e de aprendizagem se realiza mediante situações não-convencionais. Ainda, nesse contexto, a autora afirma que a EaD também pode ser vista pela ótica da democratização do ensino, visto que é também "uma opção válida para a população dispersa em lugares onde não havia escolas ou universidades ${ }^{5 "}$.

Nesse sentido, podemos afirmar que a educação a distância é um fenômeno pedagógico, uma vez que não é uma questão somente geográfica. O cerne da questão é entendermos o efeito que essa distância produz no ensino e na aprendizagem, no planejamento e na organização dos cursos da EaD. A interação a distância ${ }^{6}$ é o ponto chave para compreendermos o processo de comunicação entre professores e aluno e quais os meios de criar procedimentos diferentes na construção de instrução e na facilitação dessa interação.

\footnotetext{
${ }^{3}$ Utilizamos a classificação proposta por Moore e Kearsley no livro educação a distância: uma visão integrada.

${ }^{4}$ LITWIN, E. Educação a distância: temas para o debate de uma nova agenda educativa. Porto Alegre: ArtMed, 2001,p. 13.

${ }^{5}$ LITWIN, E. Educação a distância: temas para o debate de uma nova agenda educativa. Porto Alegre: ArtMed, 2001.p.13

${ }^{6}$ Para uma compressão mais aprofundada da teoria da educação a distância conferir: (MOORE, M; KEARSLEY, K. 2011, p.239)
} 
Segundo Moore e Kearsley (2011), quanto mais intensa é a interação a distância, mais o estudante tem que exercer sua autonomia. Em cursos muito estruturados, os estudantes têm a possibilidade de escolher, por exemplo, seus objetivos de aprendizagem e de controlar seu tempo de estudo, mas, para que isso aconteça, os professores devem incentivar tal prática.

Para teorias pedagógicas, como o construtivismo ${ }^{7}$, os estudantes devem assumir a tarefa de criar novos significados a partir do conteúdo assimilado. Nesse processo, o professor tem de proporcionar tarefas que estimulem essa autonomia, desenvolvendo atividades que permitam que o estudante construa seu próprio conhecimento. Desse modo, o professor é um facilitador no processo de ensinoaprendizagem e não apenas um reprodutor de conteúdos. Em se tratando de EaD, os avanços tecnológicos possibilitaram que uma quantidade maior de instituições escolham métodos que considerem a interação em detrimento de uma mera transmissão.

Nesse ínterim, desenvolveu-se este trabalho, com a intenção de compreender melhor as particularidades da EaD e também de refletir sobre a condição dos professores frente a essa realidade. Diante do exposto, concentramo-nos em buscar uma possível resposta para a pergunta acerca da especificidade do processo de ensino-aprendizagem na EaD. Em outras palavras: como podemos pensar a especificidade desta modalidade de ensino? Como podemos identificar à luz da teoria construtivista o papel do professor e do estudante da EaD?

\section{METODOLOGIA}

Para tanto, a metodologia de pesquisa pauta-se numa revisão de literatura especializada no assunto, evidenciando conceitos e refletindo sobre o papel dos principais agentes envolvidos com o processo educacional (professor e aluno). Este recorte se faz necessário pelo reconhecimento do caráter limitado desse tipo de produção acadêmica e não pela ignorância ou pelo desmerecimento dos outros

\footnotetext{
${ }^{7}$ O construtivismo é uma teoria que sustenta que os indivíduos não são nem meros produtos do ambiente, mas também não são apenas resultados de suas disposições internas, são resultados da interação desses dois fatores, que vão se construindo no dia-a-dia, ou seja, o conhecimento é nesse sentido uma construção do ser humano. Os principais representantes do construtivismo são: Jean Piaget, Henri Wallon,L.S Vigotsky e A.N Leontiev. Cf em ARIAS, J; YERA, A.O que é a pedagogia construtivista?. Revista educação pública, Cuiabá,v.5,n.8,Julho/Dezembro,1996.
} 
inúmeros agentes envolvidos nesse processo, tais como: coordenação geral, coordenação especializada (ou de ambientes), professores auxiliares ou assistentes ou ainda os tutores (chamados, em alguns casos, de orientadores acadêmicos), pessoal técnico (webmasters, web designers, suporte) etc.

\section{RESULTADOS E DISCUSSÃO:}

\subsection{O PAPEL DO PROFESSOR NO ENSINO A DISTÂNCIA.}

O que o presente artigo se propõe a discutir diz respeito aos novos requisitos profissionais, como por exemplo, o acesso às novas tecnologias da informação e comunicação e aos atuais padrões de uma atuação voltados para o $\mathrm{EaD}$, os quais impulsionam os professores a patamares mais elevados de profissionalização, que precisam ser objeto de reflexão, de renovação, para que cada vez mais promovam a ampliação do saber, do fazer e do saber-fazer docente.

Dito isto, gostaríamos de enfatizar preliminarmente que, no contexto geral da EaD e em relação aos papéis a serem desenvolvidos, compreendemos que a educação a distância difere completamente, em sua organização e seu desenvolvimento, do ensino oferecido de forma presencial, uma vez a tecnologia e a interatividade estão sempre presentes e exigindo uma nova postura tanto do professor como dos alunos.

Além disso, nossa reflexão, advinda da prática pedagógica efetiva, aponta como uma das características que devem ser observadas e enfrentadas, no contexto do $\mathrm{EaD}$, é a distância entre o professor e o estudante. Falamos aqui não de uma distância física, mas de uma distância na capacidade de comunicação interativa e de construção coletiva do saber. Essa "distância", há muito, vem sendo sinalizada como uma dificuldade do ensino presencial que, muitas vezes, acaba por ser constatada também e de forma agravada no contexto do $\mathrm{EaD}$, principalmente, quando o professor tenta reproduzir, nesse novo contexto educacional, velhas posturas e velhos hábitos de "sala de aula".

Assim, buscamos compreender o que teóricos, como: Peters (2006)); Moore; Kearsley;(2011) Siqueira(2001); Litwin(2001); Behrens(1996), entre outros autores, debatem acerca do papel do professor no ensino a distância, 
A leitura desses autores nos leva a compreender que o professor, ao invés de ser considerado um simples detentor do conhecimento, isto é, um exímio detentor das técnicas pedagógicas, deve ser visto como alguém capaz de "instrumentalizar os alunos, para que participem de processos coletivos, convivam e discutam com pessoas, defendam seus argumentos, inter-relacionem e integrem-se aos grupos (coletivos) para a reconstrução ou a construção de novos conhecimentos 8 ".

Desse modo, os estudantes deixam de ser apenas meros reprodutores de conteúdos já estabelecidos pelo professor e passam a ser sujeitos do seu próprio conhecimento. No entanto, na educação a distância, em grande parte das instituições de ensino, os conteúdos são estabelecidos previamente e os objetivos também. Além disso, existe uma regulamentação dos estudos e dos exames. Desse modo, podemos perceber grande influência do ensino tradicional na EaD.

Como confirma Peters:

\begin{abstract}
Ainda se faz sentir demasiadamente a influência do tradicional modelo de exposição monologal e da recepção do saber como reação a ela. Esse modelo determina o ensino universitário. Por isso, os docentes estão mais dispostos a desenvolver, com grande engajamento, cursos de ensino a distância impressos, para, desse modo, ampliar e diversificar sua oferta de ensino, do que empenharse pela defesa de um estudo autônomo (PETERS, 2006, p.97).
\end{abstract}

Outro argumento muito utilizado contra o ensino autônomo é que parte dos docentes afirmam que os estudantes não estão preparados para essa nova experiência e que seria um fracasso para os estudantes esse modelo de estudo. Para Peters (2006), é uma forma de pensar lamentável, tendo em vista que os estudos autônomos correspondem à educação a distância. Um outro aspecto que não podemos nos eximir de comentar é que o estudo autônomo, nesse contexto, não é uma construção individual. Na verdade, configura-se como um modelo que se concilia com as formas tradicionais de ensino e, para que se possa exercer essa autonomia, os professores devem oferecer o suporte inicial, a fim de que os estudantes possam ter uma base teórica capaz de prosseguir com algumas atividades de forma mais independente.

\footnotetext{
${ }^{8}$ BEHRENS, Marilda Aparecida. A formação continuada dos professores e a prática pedagógica. Curitiba: Champagnat, 1996, p.41.
} 
O papel do professor é proporcionar ao estudante essa autonomia ${ }^{9}$, atribuindo atividade que faça com que ele exerça o estudo autônomo. Atividades, como: autoestudo, seminário, elaboração de estudo dirigido e trabalhos de conclusão de curso são estratégias auxiliares que possibilitam uma construção de uma independência acadêmica.

Para Petters:

Para que os supramencionados princípios de estudo autônomo tenham sucesso no ensino a distância, docente e discente têm que adotar outra atitude em relação ao tema, pois esses princípios naturalmente não podem ser considerados, como se fez até agora, secundários, mas importantes, desejáveis, significativos e até mesmo centrais. É necessário dar-lhes mais atenção do que até agora e fomentá-los e desenvolvê-los conscientemente na medida do possível ${ }^{10}$.

Para que o modelo de ensino a distância tenha excelência, é essencial entendermos que o papel do professor é inalienável na ação de formação. Sua participação é fundamental desde a concepção do curso, a organização e elaboração de materiais midiáticos até a própria mediação e interlocução com os estudantes e outros partícipes, além da avaliação do processo. Desse modo, a introdução do perfil "conteudista" (que produz os materiais didáticos), sem considerá-lo protagonista das demais atividades, poderá enfraquecer o resultado desejado da formação (o conhecimento), por isso é necessário que o professor tenha como horizonte o aluno que ele almeja formar, se a autonomia for a habilidade central no processo de ensino aprendizagem. O docente, nesse sentido, deve elaborar os materiais, pensando em um modo que reforce essa habilidade no estudante.

Em se tratando de teoria de cunho construtivista, o papel que o professor deve exercer é de facilitador no processo de ensino-aprendizagem e não de mero reprodutor de conhecimento. Sendo assim, o docente deve criar estratégias, para que o estudante possa ser sujeito do processo de aprendizagem por meio da

\footnotetext{
${ }^{9}$ O filósofo moderno Immanuel Kant no século XVIII, identificou o papel da autonomia no processo de formação do indivíduo, no seu artigo $O$ que é a ilustração, afirma que a menoridade é a incapacidade de pensar por si mesmo, para Kant é cômodo para os homens essa menoridade, tendo em vista que é mais fácil ter outras pessoas que podem pensar por mim, então não preciso me esforça para ter meu próprio entendimento. A referência completa desse artigo encontra-se nas referências bibliográficas.

${ }^{10}$ PETERS,O, Didática do ensino a distância, Tradução de Ilson Kayser, Rio grande do sul: Unisinos, 2006.,p.165.
} 
discussão e interação. Nessa perspectiva, o estudante passa a ser construtor do seu próprio conhecimento.

Sobre o papel do professor na teoria construtivista, afirma Airas (1996) "a pedagogia construtivista é uma proposta democrática (...), o professor age como "instigador" da aprendizagem, combinando disciplina e rotina num ambiente de relativa liberdade ${ }^{11}$. Diferente da teoria de cunho tradicional, a construtivista entende o professor como mediador do conhecimento e, em se tratando do ensino a distância, é essa mediação que fornece elemento, para que o aluno ganhe, de forma progressiva, uma autonomia na sua vida acadêmica.

Não podemos deixar de acentuar que não estamos defendendo uma ausência do professor na educação a distância, mas deve existir uma independência do aluno para pesquisar, fazer as atividades e elaborar estratégias de estudos, o professor deve dar um suporte, isto é, dar um feedback nos fóruns e na correção das atividades.

Um bom professor: "cria propostas de atividades para a reflexão, apoia sua resolução, sugere fontes de informação alternativas, oferece explicações, facilita os processos de compreensão; isto é, guia, orienta, apoia, e nisso consiste seu ensino $^{12 " .}$ Nesse contexto, podemos recorrer a uma última definição do papel do professor em EaD: "mais do que ensinar, trata-se de fazer aprender (...), concentrando-se na criação, na gestão e na regulação das situações de aprendizagem $^{13 "}$. O professor atua como facilitador, incentivador, investigador do saber, da sua prática e da aprendizagem individual e coletiva.

Assim, podemos destacar que devemos repensar o papel do professor, para que não se reproduzam, nos atuais ambientes de educação a distância, as tradicionais práticas e concepções a respeito dele. O professor, como reprodutor de informações e fórmulas, deve dar lugar a um agente orientador, dinamizador e organizador da construção do conhecimento do aluno em direção à autonomia intelectual $^{14}$. Para compreendermos, de forma mais aprofundada, como em

\footnotetext{
${ }_{11}^{11}$ ARIAS, José O. Cardentey ; YERA, Armando Pérez . O que é a pedagogia construtivista? Disponível em:<http://ie.ufmt.br/revista/userfiles/file/n08/8_O_fazer_pedagagico. pdf>Acesso em: 30 ago. 2011.

${ }_{12}^{12}$ LITWIN, E. Educação a distância: temas para o debate de uma nova agenda educativa. Porto Alegre: ArtMed, 2001,p.99.

${ }^{13}$ ALMEIDA, Fernado José et al. Educação a distância: Formação de professores em ambientes virtuais e colaborativo de aprendizagem. São Paulo, Projeto NAVE, 2001,139.

${ }_{14}$ Por autonomia intelectual entendemos como a capacidade gradativa do estudante promover sua aprendizagem de forma independente.
} 
situações de EaD, é valioso promover o estudo autônomo. Ademais, é essencial entendermos que atitudes os estudantes devem tomar para alcançar tal objetivo. Desse modo, tendo em vista as discussões sobre o papel do professor, resta-nos discutir como o estudante pode promover essa postura.

\section{O PAPEL DO ESTUDANTE NA EAD}

Antes de adentrarmos efetivamente na discussão acerca do papel do estudante, tendo, como pano de fundo, a teoria construtivista na educação a distância, acreditamos ser essencial entendermos os componentes básicos, para que o docente possa acompanhar a aprendizagem nessa modalidade de ensino. Um ponto primordial é o acesso à internet, às TICs, envolvidas no processo e a experiência mínima em informática, elementos que, muitas vezes, são negligenciados, pois muitos alunos dessa modalidade, por morarem em áreas afastadas das capitais, têm um acesso restrito à internet e apresentam uma dificuldade no que diz respeito ao manuseio do computador.

Tendo em vista essas exigências, é relevante entendermos qual o perfil dos alunos que procuram a EaD. Normalmente, são adultos que já têm um emprego, obrigações socais e família. Uma das vantagens que podemos acentuar nessa modalidade de ensino em relação ao presencial é a flexibilidade, visto que o aluno pode, na maioria das vezes, escolher a hora de estudar e iniciar os estudos, uma vez que cada aluno tem um ritmo diferente de estudo e, nesse sentido, essa modalidade permite que o aluno imponha, até certo ponto, seu ritmo individual de aprendizagem.

Além disso, outra vantagem da educação a distância é a possibilidade de distribuir educação para muitas pessoas que não têm acesso a outras modalidades por diversos motivos, como por exemplo: população rural, idosos, pais com filhos ainda na infância, entre outros. Nesse caminho, a educação a distância se faz presente em situações em que outros modelos de educação estão ausentes.

No entanto, também existem algumas desvantagens quanto ao ensino a distância, como por exemplo: os alunos podem se sentir isolados por terem que fazer seus trabalhos e pesquisas "sozinhos". Nesse sentido, é importante que o aluno tenha uma motivação, para que ele não desista do curso, visto que grande 
parte da evasão, nos cursos da EAD, ocorre por esses motivos (dificuldades técnicas e/ou desmotivação), pois os cursos no ensino a distância tornam-se muito "teóricos" e os alunos tendem a se sentir desinteressados pelos conteúdos.

Para Moore e Kearsley (2011), preocupações extracurriculares, tais como: família e emprego podem afetar, de forma negativa, a conclusão do curso. Pode-se citar, como exemplo, a falta de incentivo por parte dos familiares, produzindo, assim, um efeito negativo no estudante e, consequentemente, interferindo no seu desenvolvimento no decorrer do curso.

Outro ponto discutido por Moore(2011) é que aptidões de estudo determinam o sucesso das aulas pela internet. Assim, estudantes que planejam seu tempo melhor têm a possibilidade maior de concluir o curso do que aqueles que esperam para responder os fóruns e atividades no final do prazo ou deixam de fazer as atividades online. No entanto, cabe ao professor e ao aluno procurar meios, para que, mesmo com todas as limitações, estas sejam superadas. Ademais, não podemos deixar de acentuar que o professor, nesse processo, é visto como apresentador do conhecimento, isto é, seu papel é desenvolver situações de aprendizagem que possibilitem que os estudantes construam seu próprio conhecimento.

Tendo em vista que o foco no presente artigo é a educação a distância na era da internet, o professor deve criar ferramentas, para que o estudante desenvolva essa autonomia. É importante ressaltar que não estamos defendendo que o professor não acompanhe os estudantes ao longo do curso, mas que ele, gradualmente, dê ferramentas, para que o aprendiz se torne mais independente.

Segundo Moore e Kearsley ${ }^{15}$, "as pessoas mais independentes (isto é, relativamente menos influenciadas pelo ambiente ao redor, incluindo o ambiente social) são mais bem preparadas para educação a distância do que as pessoas menos independentes do meio". Desse modo, é fundamental que o professor pense em eficientes ferramentas para desenvolver essa capacidade no aprendiz na hora de elaborar o curso.

$\mathrm{Na} \mathrm{EaD}$, o aluno passa a ser agente efetivo no processo educacional, pois a aprendizagem dependerá muito do seu interesse e de suas ações para se efetivar. Nessa modalidade, existe uma distância entre professor e aluno. Posto isso, o aluno

\footnotetext{
${ }^{15}$ MOORE, M; KEARSLE, G, Educação a distância: uma visão integrada, Tradução de Roberto Galman, São Paulo: Cengage Learning, 2011, p.183.
} 
necessita assumir um papel ativo e cooperar com os professores e colegas, para que possam, em conjunto, realizar uma aprendizagem significativa.

No entanto, na EaD, há uma herança muito enraizada do ensino presencial, que, por sua vez, reforça uma postura passiva por parte dos alunos, diferente da teoria construtivista que realça o papel ativo de parte dos educandos.

Para Ferreiro e Teberosky ${ }^{16}$, "o sujeito a quem a escola se dirige é um sujeito passivo, que não sabe a quem é necessário ensinar, e não um sujeito ativo, que não somente define seus próprios problemas, mas que além disso constrói espontaneamente os mecanismos para resolvê-los."

Além disso, podemos acentuar que o perfil da maioria dos alunos dessa modalidade é de adultos, porque exige uma autonomia por parte dos discentes e o sucesso do EaD depende muito da postura do aluno nas suas responsabilidades diante do processo educacional. Enquanto, no ensino presencial, o foco está no professor, no ensino a distância, o discente assume o papel principal. No que se refere ao aluno:

Ele é privilegiado na relação que tem com a tecnologia. Ele aprende rapidamente navegar, sabe trabalhar em grupo e tem certa facilidade de produzir materiais audiovisuais. Por outro lado, o aluno tem dificuldade de mudar aquele papel passivo de executor de tarefas, (...). Na prática, acaba assumindo um papel bastante passivo em relação a suas reais potencialidades ${ }^{17}$.

O professor do ensino a distância deve ter a sensibilidade de perceber que os alunos não são homogêneos e que essa modalidade de ensino é escolhida pelos estudantes pelas mais diversas razões. Basicamente, percebemos dois perfis de alunos nessa modalidade, a saber: o aluno tradicional e o aluno aprendiz.

Enquanto o primeiro prepara-se somente para memorizar as informações, não estabelece a relação de trocas entre colegas e professores; recebe passivamente os conteúdos ministrados sem se questionar a respeito e, nas atividades e avaliações, apresenta apenas respostas prontas e memorizadas, o segundo, ou seja, o aluno aprendiz tem a habilidade de ler criticamente e reelaborar os conteúdos ministrados pelos docentes, colabora com os colegas e professores, ou seja, questiona inventa

\footnotetext{
${ }^{16}$ FERREIRO, Emilia; TEBEROSKY, Ana. Aprendizagem da leitura e da escrita. In: GADOTTI, M (Org). História das ideias pedagógicas. São Paulo: Ática, 2003, p 229.

${ }^{17}$ MORAN, J. M., MASETTO, M. T. \& BEHRENS, M. A. Novas tecnologias e mediação pedagógica. Campinas, SP: Papirus, 2000, p.134.
} 
novas soluções e está aberto às discussões; procura reconstruir o que aprendeu, não apenas memoriza os conteúdos. O aluno aprendiz entende que é importante reconhecer suas dificuldades e procure superá-las, pois compreende que a aprendizagem, nessa modalidade, depende mais dele. Desse modo, é interessante que o aluno aprendiz seja visto como um modelo a seguir, para que ocorra realmente uma aprendizagem e não apenas uma memorização de informações.

Diante do que foi discutido, podemos perceber que o papel do aluno à luz da teoria construtivista na educação a distância não se limita apenas a participar dos fóruns de discussões e chats, ou seja, o uso adequado da tecnologia é essencial, no entanto, não garante o sucesso nessa modalidade.

Nessa direção, o discente precisa ter consciência de que ele é responsável por construir o seu próprio conhecimento. Dessa forma, não deve comportar-se apenas como um objeto das opiniões alheias, reproduzindo ideias e condutas sem reflexões, pelo contrário, deve assumir o papel de sujeito ativo, que maneja as informações provenientes do ambiente circundante.

\section{CONSIDERAÇÕES FINAIS}

Tivemos como objetivo compreender o papel do professor e do estudante a partir da ótica da teoria construtivista. Para isso, mantivemos nossa atenção na quinta geração da educação a distância. Num primeiro momento, vimos os papéis que os professores e o aluno desempenham no ensino a distância, para que possam construir um ensino-aprendizagem significativo, exercendo, assim, com excelência e responsabilidade as funções que lhes cabem.

Além disso, acentuamos que, no processo de ensino e aprendizagem, cabe ao docente estimular o raciocínio do aprendiz, criando situações que incentivem a argumentação e a contra- argumentação, possibilitando, por conseguinte, uma reflexão sobre os conteúdos. Desse modo, tanto o professor quanto o aluno têm de assumir um comportamento ativo, a fim de que ocorra uma aprendizagem significativa.

$\mathrm{Na}$ educação a distância, deve-se ter a preocupação com a evolução tecnológica e a evolução pedagógica, pois, como já discutido, o professor tem um papel fundamental no sucesso da EaD. Quando o professor tenta reproduzir, nesse 
novo contexto da educação, velhas posturas e velhos hábitos de "sala de aula", os alunos perdem a possibilidade de se tornarem aprendizes, transformando-se em discentes que memorizam e reproduzem os conteúdos ministrados pelo professor. Nesse sentido, podemos afirmar que o professor, ao invés de ser somente detentor do conhecimento, deve ser também alguém capaz de instigar os discentes a participem de processos formadores de caráter coletivo, provocando o convívio e a discussão com os colegas e com outras pessoas na "web". Diante disso, estimular essas competências e atitudes nos alunos significa fornecer-Ihes ferramentas, para que possam refletir sobre o seu papel no processo educacional.

Sendo assim, o professor, nesse processo, deve:

1. Elaborar a disciplina, de forma que estimule a autonomia dos alunos, possibilitando-Ihes que, gradualmente, aprendam de modo mais independente;

2. Valorizar questões levantadas pelos estudantes e incitá-los, para que tenham a habilidade de construir novos conhecimentos;

3. Desenvolver técnicas, para que a disciplina estimule os alunos a continuarem no curso, uma vez que há muita desistência. Salienta-se que boa parte dessa evasão decorre de fatores externos, como família e trabalho, e ainda internos, como a inabilidade dos estudantes a se adequarem ao ensino a distância.

No entanto, assim como professor na educação a distância tem de mudar os velhos hábitos tradicionais, o aluno também precisa se posicionar como sujeito construtor do seu conhecimento, que se prepara não somente para memorizar informações, mas que possa reconstruir o que aprendeu e assim buscar novas respostas.

Para a teoria construtivista, o aprendiz deve sempre estar engajado na construção do conhecimento. Este, por sua vez, coloca como tarefa a construção do seu próprio conhecimento, pois tem a possibilidade de escolher onde, por quanto tempo e em que ritmo irá estudar. Nesse sentido, o indivíduo tem a responsabilidade de construir significados novos a partir do conteúdo apresentado pelo professor. É interessante observar que a teoria construtivista se encaixa de maneira excepcional no modelo de educação a distância, mais precisamente naqueles cursos que têm como ferramenta fundamental o uso da internet.

Além disso, pode-se afirmar que a postura do aluno é um ponto decisivo para o sucesso da educação a distância. O discente que interage, coopera e reconstrói o conhecimento, além de tornar-se ator do seu próprio conhecimento, também se 
torna uma motivação, para que o professor repense em suas metodologias. Por fim, é essencial entendermos que o papel do professor e o dos estudantes estão interligados, já que as duas partes têm responsabilidades no processo educacional e, em se tratando da educação a distância, essas funções devem ser inteligíveis, para que o professor tenha clareza do perfil do estudante que almeja formar e que, por conseguinte, o estudante tenha como horizonte o que deve ser feito, para que obtenha excelência na aprendizagem.

\section{REFERÊNCIAS}

ARIAS, José O. Cardentey. YERA, Armando Pérez. O que é a pedagogia construtivista?

Disponível em:<http://ie.ufmt.br/revista/userfiles/file/n08/8_O_fazer_pedagagico. pdf> Acesso em: 30 ago. 2011.

ALMEIDA, Fernado José et al. Educação a distância: Formação de professores em ambientes virtuais e colaborativo de aprendizagem. São Paulo: Projeto NAVE, 2001.

ARIAS, J; YERA, A.O que é a pedagogia construtivista? Revista educação pública, Cuiabá, v.5, n.8, Julho/Dezembro,1996.

BEHRENS, Marilda Aparecida. A formação continuada dos professores e a prática pedagógica. Curitiba: Champagnat, 1996.

FERREIRO, Emilia; TEBEROSKY, Ana. Aprendizagem da leitura e da escrita. In: GADOTTI, M (Org). História das ideias pedagógicas. São Paulo: Ática, 2003.

KANT, I. Textos Seletos. 2. ed. (Trad.) Floriano de Souza Fernandes. Petrópolis: Vozes, 1985.

LITWIN, E. Educação a distância: temas para o debate de uma nova agenda educativa. Porto Alegre: ArtMed, 2001.

MOORE, M; KEARSLE, G. Educação à distância: uma visão integrada, Tradução de Roberto Galman, São Paulo: Cengage Learning, 2011.

MORAN, J. M., MASETTO, M. T. \& BEHRENS, M. A. Novas tecnologias e mediação pedagógica. Campinas, SP: Papirus, 2000.

PETERS, O. Didática do ensino a distância. Tradução de llson Kayser, Rio grande do Sul: Unisinos, 2006.

SIQUEIRA, Marli Aparecida da Silva. Monografias e teses: das normas técnicas ao projeto de pesquisa: teoria e prática. Brasília: Editora Consulex, 2005. 